
of the Main Results from the Final Symposium

(C) 2018 by the Arizona Board of Regents on behalf of the University of Arizona. This is an Open Access article, distributed under the terms of the Creative Commons Attribution licence (http://creativecommons. org/licenses/by/4.0/), which permits unrestricted re-use, distribution, and reproduction in any medium, provided the original work is properly cited.

\title{
IDENTIFICATION OF CHEMICAL FORM OF STABLE CARBON RELEASED FROM TYPE 304L AND 316L STAINLESS-STEEL POWDERS IN ALKALINE AND ACIDIC SOLUTIONS UNDER LOW-OXYGEN CONDITIONS
}

\author{
Ryo Nakabayashi* • Tomonari Fujita \\ Radiation Safety Research Center, Nuclear Technology Research Laboratory, Central Research Institute of Electric \\ Power Industry (CRIEPI), 2-11-1 Iwadokita, Komae-shi, Tokyo 201-8511, Japan.
}

\begin{abstract}
The chemical form of ${ }^{14} \mathrm{C}$ released from irradiated stainless steel is a key parameter in the safety assessment of the subsurface disposal system in Japan. In this study, to identify the chemical form of the released carbon, unirradiated stainless-steel powders, which were found to be water-atomized powders with a silicon oxide film, were immersed in $\mathrm{NaOH}$ and $\mathrm{HCl}$ solutions under low-oxygen conditions for approximately 25 days. The results showed that the main chemical forms of the carbon were colloidal carbon in the $\mathrm{NaOH}$ solution and colloidal carbon and formic and acetic acids in the $\mathrm{HCl}$ solution. Almost no hydrocarbons were detected in both solution systems. Concerning the source of the colloidal carbon and carboxylic acids, the hypothesis that carbon in the oxide layer is released is considered to be reasonable. The very small amounts of hydrocarbons generated prevented us from discussing the source of the hydrocarbons. To validate the hypothesis and obtain further information on the hydrocarbons, additional experiments are necessary. In particular, for long-term safety assessment, it is important to determine whether the colloidal carbon, carboxylic acids and hydrocarbons are continuously released during the corrosion process. Therefore, information on the temporal evolution of the carbon should be obtained.
\end{abstract}

KEYWORDS: ${ }^{12} \mathrm{C}$, chemical form, corrosion, water-atomized stainless-steel powder.

\section{INTRODUCTION}

The chemical form of radiocarbon $\left({ }^{14} \mathrm{C}\right)$ released from low-level waste (e.g., irradiated control rods, channel boxes and burnable poisons of spent fuel, which are composed of stainless steel) is a key parameter in the safety assessment of the sub-surface disposal system in Japan (Yamato 2006; Nuclear Safety Commission of Japan 2007). Most of the radionuclides released from the waste will sufficiently decay in the disposal facility owing to the multibarrier system. However, whether or not ${ }^{14} \mathrm{C}$, which has a long radioactive half-life (5730 yr), will sufficiently decay in the disposal facility depends on its chemical form. This indicates that it is necessary for the safety assessment to determine the chemical form of ${ }^{14} \mathrm{C}$ released from the waste under the disposal conditions (highly alkaline and low-oxygen conditions). To determine the release behavior of ${ }^{14} \mathrm{C}$ from irradiated stainless steels, immersion experiments were previously carried out using non-irradiated type 304L and 316L stainless-steel powders in $0.005 \mathrm{M} \mathrm{NaOH}$ solutions (of approximately $\mathrm{pH} 12$ ) under low-oxygen conditions (Nakabayashi and Fujita 2017). Given the low corrosion rate of stainless steel in alkaline solutions under low-oxygen conditions (Blackwood et al. 2002; Mihara et al. 2002) and the low carbon content $(<0.03 \mathrm{wt} \%)$ in type $304 \mathrm{~L}$ and $316 \mathrm{~L}$ stainless steels, the amount of carbon released from the stainless-steel samples with a low reactive surface area, such as steel chips, to the liquid and gas phases during the short-term immersion periods was expected to be very low. Therefore, powdered stainless steels with a large reactive surface area were used in the previous study to detect the contents of released carbon in the liquid and gas phases.

The results showed that the main chemical form is colloidal carbon (Nakabayashi and Fujita 2017). The carbon species that could not penetrate the ultrafiltration membranes $(10,000$

\footnotetext{
*Corresponding author. Email: r-naka@criepi.denken.or.jp.
} 
molecular weight cutoff [MWCO]) are referred to as colloidal carbon. If the chemical form of ${ }^{14} \mathrm{C}$ released from low-level waste under the disposal conditions is colloidal carbon, most of the

${ }^{14} \mathrm{C}$ will be retained for a sufficient time and decay in the disposal facility owing to the effect of the filtration property of the engineered barrier (i.e., bentonite). In the safety assessment, this can lead to a reduced dose derived from ${ }^{14} \mathrm{C}$. In the previous study, it was shown by thermodynamic calculation that metallic compounds (e.g., iron hydroxide) can be formed in the solution. In addition, Nakabayashi and Fujita (2017) observed the aggregation of colloid-like particles using a scanning electron microscope (SEM), and a point analysis of the aggregate by energy-dispersive $\mathrm{X}$-ray spectroscopy (EDS) showed that carbon was present with iron and chromium in the aggregate. On the basis of these results, it was pointed out in the previous study that the colloidal carbon may be formed by the sorption of carbon on metallic compounds. However, it is considered that the experimental evidence is not sufficient to validate this assumption.

For example, information on the stainless-steel powders used in the previous study was lacking. The analysis of liquid samples showed that the silicon and total organic carbon (TOC) concentrations in the unfiltered liquid samples were very high $(\sim 4000 \mu \mathrm{mol} / \mathrm{L}$ and $\sim 200 \mu \mathrm{mol}-\mathrm{C} / \mathrm{L}$, respectively), as shown in Figures 2 and 3 of Nakabayashi and Fujita (2017). The concentrations of silicon and TOC were higher than that of iron in the liquid samples. However, the silicon and carbon contents in the bulk steels were less than the iron content from mill test reports (Table 1 of Nakabayashi and Fujita 2017). To understand the release behavior of these elements (particularly carbon) from the steels, the stainless-steel powders used in the study should be characterized. To clarify the formation mechanism of colloidal carbon, an immersion experiment under acidic conditions will also be necessary. Assuming that colloidal carbon is formed by the sorption of carbon on a metallic hydroxide under an alkaline condition, colloidal carbon will not form in an acidic solution owing to the low stability of the metallic hydroxide. The ionic form of metallic elements such as iron and chromium is more thermodynamically stable than the metallic hydroxides (Stumm and Morgan 1996).

Therefore, in this study, we carried out immersion experiments using type 304L and 316L stainlesssteel powders, which were used in the previous study (Nakabayashi and Fujita 2017), in $\mathrm{NaOH}$ solutions (of approximately $\mathrm{pH} 12$ ) and $\mathrm{HCl}$ solutions (of approximately $\mathrm{pH} 2$ ) under low-oxygen conditions with the aim of obtaining further data to discuss the chemical form of the carbon released from the stainless-steel powders. To compare the results for the alkaline and acidic systems, it is essential to obtain results from experiments performed under the same conditions as much as possible. This is because there are many potential contaminant sources of stable carbon, such as Milli-Q water, the laboratory wares and the analytical instruments used in the experiment. It is considered that the contamination level could potentially change depending on the time and situation.

\section{MATERIALS AND METHODS}

To exclude the potential effect of microorganisms on the chemical form of stable carbon released from the stainless-steel powders, the laboratory wares, such as glass ampoules, pipette

Table 1 Nominal compositions of type 304L and 316L stainless-steel powders used in this study $(\mathrm{wt} \%)$.

\begin{tabular}{llllllllll}
\hline Sample & $\mathrm{C}$ & $\mathrm{Cr}$ & $\mathrm{Fe}$ & $\mathrm{Mn}$ & $\mathrm{Mo}$ & $\mathrm{Ni}$ & $\mathrm{P}$ & $\mathrm{S}$ & $\mathrm{Si}$ \\
\hline Type 304L & 0.016 & 19.11 & Balance & 0.16 & - & 11.23 & 0.021 & 0.002 & 0.87 \\
Type 316L & 0.013 & 16.50 & Balance & 0.06 & 2.47 & 11.16 & 0.012 & 0.013 & 1.00 \\
\hline
\end{tabular}


tips and Teflon bottles, and deionized Milli-Q water were sterilized in an autoclave (LSX-700, Tomy Seico Co. Ltd., Japan) for $30 \mathrm{~min}$ at $121^{\circ} \mathrm{C}(200 \mathrm{kPa})$ prior to use. To prevent the contamination of oxygen and carbon dioxide from air, two gloveboxes (100\% Ar atmosphere, $<0.1 \mathrm{ppm}$ of $\mathrm{O}_{2}$ ) were used in this experiment. One of the gloveboxes was used only to wash the stainless-steel powders with $\mathrm{HCl}$ solution. The other was used for other experimental work, such as to prepare solutions, to add the stainless-steel powders and solutions to ampoules and to collect liquid and gas phases in the ampoules. This was to avoid the contamination of hydrocarbons, which may be produced by the stainless steel/solution interaction, in the atmosphere of the glovebox. Here, we defined the former and latter gloveboxes as "glovebox 1" and "glovebox 2 ," respectively. Note that the transfer of the solutions and stainless steels between glovebox 1 and glovebox 2 was carried out as quickly as possible.

\section{Stainless Steels}

The types 304L (particle size under $150 \mu \mathrm{m}$, Lot No. 28N1001, The Nilaco Corp., Japan) and 316L (particle size under $45 \mu \mathrm{m}$, Lot No. 23365400, Strem Chemicals, Inc., USA) stainless-steel powders used in the previous study (Nakabayashi and Fujita 2017) were also used in this experiment. Note that these powders are commercially available as type 304 and 316 stainlesssteel powders, respectively. The nominal bulk compositions of these powders are compiled in Table 1, which were taken from mill test reports provided by the suppliers. The carbon contents of these stainless-steel powders are less than $0.03 \mathrm{wt} \%$, indicating that they should essentially be defined as type $304 \mathrm{~L}$ and $316 \mathrm{~L}$ stainless-steel powders. The powders were washed with Ar-purged $0.01 \mathrm{M} \mathrm{HCl}$ solution for $30 \mathrm{~min}$ then rinsed 15 times with Ar-purged Milli-Q water. This pretreatment was conducted in an ultrasonic bath under Ar atmosphere using glovebox 1 . Then the powders were dried in a desiccator under vacuum. The desiccator with the powders was moved to glovebox 2 and kept in glovebox 2 prior to use.

\section{Chemicals}

Deionized Milli-Q water (18 M $\Omega \cdot \mathrm{cm}$ resistivity, Merck Ltd., Japan) was purged by Ar gas $(99.999 \%)$ in Ar-filled glovebox 2 for $1 \mathrm{hr}$, which was used throughout this experiment. A 0.005 $\mathrm{M} \mathrm{NaOH}$ (approximately $\mathrm{pH} 11.8$ at $25^{\circ} \mathrm{C}$ ) solution was prepared with $\mathrm{NaOH}$ pellets $(99.99 \%$ trace metal basis, under $1 \% \mathrm{Na}_{2} \mathrm{CO}_{3}$ impurity, 306576, Sigma-Aldrich Japan Corp., Japan). $0.005 \mathrm{M} \mathrm{HCl}$ (approximately pH 2 at $25^{\circ} \mathrm{C}$ ) solution was prepared with $35-37 \% \mathrm{HCl}$ solution (guaranteed reagent, 080-01066, Fujifilm Wako Pure Chemical Corp., Japan). HCl was also used to wash the powders. After their preparation, these solutions were purged by Ar gas again in Ar-filled glovebox 2.

\section{Experimental System}

Glass ampoules with a breakable glass film were used in this experiment. The dimensions of the ampoule are shown in Figure 1. In glovebox 2, each of the powders $(70 \mathrm{~g})$ after washing was added to the glass ampoules. Then the ampoules were filled with $70 \mathrm{~mL}$ of $0.005 \mathrm{M} \mathrm{NaOH}$ solution or $0.005 \mathrm{M} \mathrm{HCl}$ solution. Three ampoules containing the powder and solution were prepared for each system. Two ampoules containing no stainless steel were filled with $0.005 \mathrm{M}$ $\mathrm{NaOH}$ or $\mathrm{HCl}$ solution as blank samples. The ampoules were attached with a needle valve and flange (Model No. KV-255-UP for BELSORP-18 Plus, MicrotracBEL Corp., Japan) and an O-ring (14.6 mm o.d., $9.8 \mathrm{~mm}$ i.d.), and the Ar gas in the ampoules was then replaced with He gas $(99.999 \%)$ by evacuating the ampoule and filling it with the He gas three times. This was to reduce the Ar peak, which overlaps the methane peak, in the subsequently obtained gas chromatogram. After the replacement, the pressure in the ampoules was reduced to $19.5 \mathrm{inHg}$ 


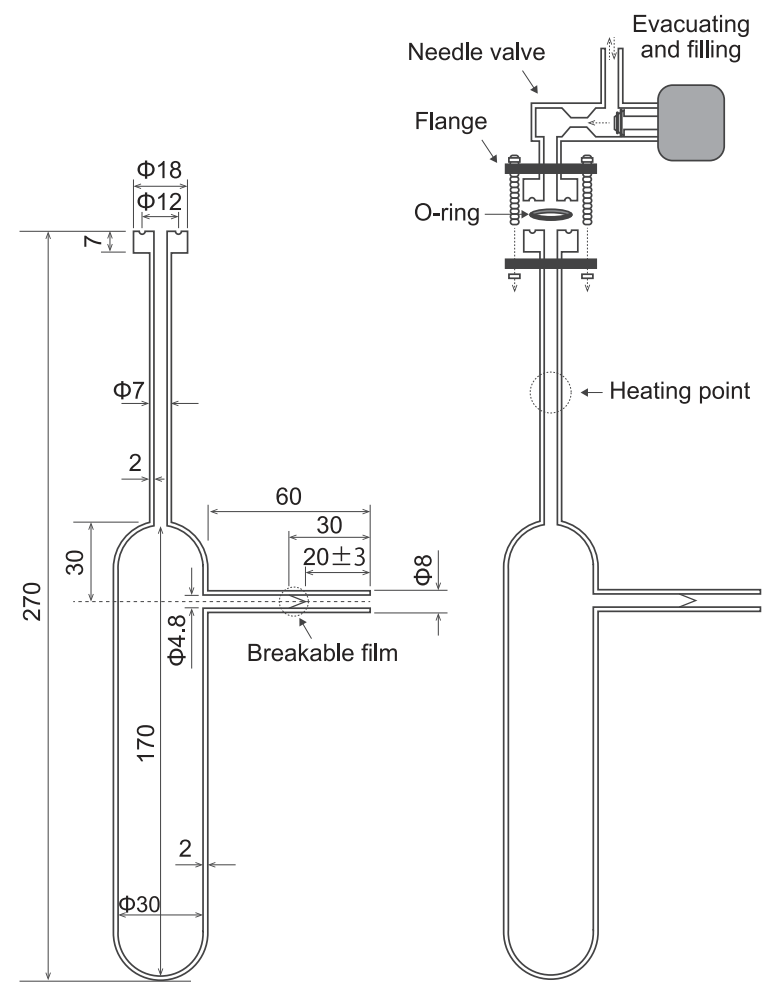

Figure 1 Glass ampoule with breakable glass film used in the experiment.

(i.e., $66035 \mathrm{~Pa}$ ) and the needle was closed. The ampoules were removed from glovebox 2 and sealed by heating the top part in air. The volume of the gas phase in the sealed ampoule was approximately $30 \mathrm{~mL}$. The sealed ampoules were placed in a desiccator containing water and the desiccator was evacuated, during which it was visually observed whether air bubbles escaped from the ampoules. The ampoules without a hole were placed in a thermostatic oven with a temperature of $25^{\circ} \mathrm{C}$ for approximately 20 to 30 days. During the experiment, the ampoules were stirred by hand for $1 \mathrm{~min}$ a day.

After the immersion period, the ampoules were moved into glovebox 2. The spout of the ampoules with the breakable film was capped with silicone cepta, and the gas phase was collected by breaking the film using a $1 \mathrm{~mL}$ Hamilton SampleLock syringe (P/N 81356, GL Sciences Inc., Japan). The syringe was then locked to prevent contamination with air. The syringe was moved outside glovebox 2 and the gas sample was analyzed by gas chromatography. Note that the syringe was washed with He gas (>99.999\%) until the gas in the syringe was under the limit of detection of the target species. During the analysis of the gas, the ampoules were kept in glovebox 2. After analyzing the gas phase, the top part of the ampoule was cut with a glass cutter, and approximately $50 \mathrm{~mL}$ of the liquid phase was collected in a $200 \mathrm{~mL}$ Teflon bottle by decantation as carefully as possible to avoid the contamination of the stainless-steel powder. After that, the liquid samples collected from the same experimental system were mixed together in a single Teflon bottle. In addition, the approximately $150 \mathrm{~mL}$ of collected liquid samples was divided into unfiltered and filtered samples with the same volume. The filtered sample was filtered using an 
ultrafiltration membrane (10,000 MWCO, Biomax polyethersulfone, $63.5 \mathrm{~mm}$ diameter, Merck Ltd.) in glovebox 2 prior to liquid analysis. Immediately before the sample was filtered, the membrane filter was rinsed with $1 \mathrm{~L}$ of $0.005 \mathrm{M} \mathrm{NaOH}$ or $0.005 \mathrm{M} \mathrm{HCl}$ solution, depending on the immersion solution in the ampoule. This was to exclude carbon originating from the filter. The oxidation-reduction potential (ORP), dissolved oxygen (DO) and $\mathrm{pH}$ of the unfiltered and filtered samples were measured in glovebox 2. For the other analyses of the liquid samples, it was necessary to remove the samples from glovebox 2 and analyze them in air. Therefore, the analyses were conducted as soon as possible to reduce the contamination with air.

\section{Analytical Methods}

\section{Chemical Depth Profile Analysis}

The chemical depth profiles of the stainless-steel powders were obtained by scanning Auger electron spectroscopy/microscopy (SAM670, ULVAC-PHI, Inc., Japan). The washed samples were probed using a $10 \mathrm{kV}$ electron beam operating with an emission current of $20 \mathrm{nA}$ at an angle of $30^{\circ}$ from the sample normal. Etching of the sample surfaces was performed by a $2 \mathrm{kV}$ argon ion beam at an etching rate of $5.3 \mathrm{~nm} / \mathrm{min}$ on the basis of calibration with $\mathrm{SiO}_{2}$.

\section{Gas Chromatography Analysis for Hydrocarbons, Carbon Monoxide and Hydrogen}

Hydrocarbons (methane, ethyne, ethene, ethane, propene, propane, methylpropane, butane), carbon monoxide and hydrogen were measured using a gas chromatograph (GC-2010, Shimadzu Scientific Instruments Inc., Japan) equipped with a barrier discharge ionization detector. Separation was carried out in a MICROPACKED ST column ( $2 \mathrm{~m}$ length, $1.0 \mathrm{~mm}$ i.d., Shinwa Chemical Industries Ltd., Japan) with He gas $(99.999 \%)$ used as the carrier gas $(7 \mathrm{~mL} / \mathrm{min})$. The detector and injection temperatures were 310 and $100^{\circ} \mathrm{C}$, respectively, and $0.2 \mathrm{~mL}$ of the sample was injected into the gas chromatograph with the split ratio set at 1:4. The gas chromatograph oven temperature was programmed to be $35^{\circ} \mathrm{C}$ for $2.5 \mathrm{~min}$, then increased at a rate of $20^{\circ} \mathrm{C} / \mathrm{min}$ to $270^{\circ} \mathrm{C}$ from 2.5 to $14.25 \mathrm{~min}$, then increased at a rate of $15^{\circ} \mathrm{C} / \mathrm{min}$ to $275^{\circ} \mathrm{C}$ from 14.25 to $14.58 \mathrm{~min}$, fixed at $275^{\circ} \mathrm{C}$ from 14.58 to $17.58 \mathrm{~min}$, increased at a rate of $15^{\circ} \mathrm{C} / \mathrm{min}$ to $305^{\circ} \mathrm{C}$ from 17.58 to $19.58 \mathrm{~min}$, and fixed at $305^{\circ} \mathrm{C}$ from 19.58 to $30.58 \mathrm{~min}$.

The calibration standards for these measurements were prepared with the following reference gases: methane (grade 99.9\%, 1020-11001, GL Sciences Inc.), ethyne (grade 0.1\%, 1020-11004, GL Sciences Inc.), ethene (grade 99.5\%, 1020-11003, GL Sciences Inc.), ethane (grade 99.5\%, 1020-11002, GL Sciences Inc.), propene (grade 99.5\%, 1020-11006, GL Sciences Inc.), propane (grade 99.5\%, 1020-11005, GL Sciences Inc.), methylpropane (grade 6.0\%, 1020-11008, GL Sciences Inc.), butane (grade 9.0\%, 1020-11007, GL Sciences Inc.), carbon monoxide (grade 99.9\%, 1020-11220, GL Sciences Inc.), carbon dioxide (grade 99.9\%, 1020-11221, GL Sciences Inc.) and hydrogen (grade 99.99\%, 1020-11201, GL Sciences Inc.). Note that carbon dioxide was not measured in the gaseous samples, although the calibration standard gas contained carbon dioxide. This is due to the difficulty of avoiding the contamination with carbon dioxide from air.

$200 \mathrm{~mL}$ vacuum sampling bottles $(\varphi 45 \times 280 \mathrm{~mm}, 3008-58102$, GL Sciences Inc. $)$ and $1000 \mathrm{~mL}$ vacuum sampling bottles $(\varphi 80 \times 360 \mathrm{~mm}, 3008-58110$, GL Sciences Inc.) were evacuated for $5 \mathrm{~min}$ and refilled with $\mathrm{He}$ gas $(99.999 \%)$ up to atmospheric pressure. To avoid the contamination with impurity gases, this process was conducted three times.

$7 \mathrm{~mL}$ of $\mathrm{He}$ gas was withdrawn from the $200 \mathrm{~mL}$ vacuum sampling bottle filled with He gas using a $10 \mathrm{~mL}$ Hamilton SampleLock syringe (P/N 81656, GL Sciences Inc.). Then, $1 \mathrm{~mL}$ each of the ethene, ethane and propane reference gases and $4 \mathrm{~mL}$ of the propene reference gas were 
added to the vacuum sampling bottle using a $1 \mathrm{~mL}$ Hamilton SampleLock syringe (P/N 81356, GL Sciences Inc.). 7.6 and $15.2 \mathrm{~mL}$ of He gas were withdrawn from the $1000 \mathrm{~mL}$ vacuum sampling bottles filled with He gas using the 1 and $10 \mathrm{~mL}$ syringes, respectively. After that, the methane $(0.05 \mathrm{~mL})$, ethyne $(5 \mathrm{~mL})$, methylpropane $(0.5 \mathrm{~mL})$, butane $(0.5 \mathrm{~mL})$, carbon monoxide $(0.05 \mathrm{~mL})$, and carbon dioxide $(0.1 \mathrm{~mL})$ reference gases and $1 \mathrm{~mL}$ of a mixture gas containing ethene, ethane, propane, and propene in the $200 \mathrm{~mL}$ vacuum sampling bottle were added to the $1000 \mathrm{~mL}$ vacuum sampling bottles with $992.4 \mathrm{~mL}$ of $\mathrm{He}$ gas. The concentrations of the compounds in these bottles, that is, methane, ethyne, ethene, ethane, propene, propane, methylpropane, butane, carbon monoxide and carbon dioxide, were 50, 5, 5, 5, 20, 5, 30, 45, 50, and $100 \mathrm{ppm}$, respectively. This mixture gas was one of the calibration standard gases. Similarly, the methane $(0.1 \mathrm{~mL})$, ethyne $(10 \mathrm{~mL})$, methylpropane $(1 \mathrm{~mL})$, butane $(1 \mathrm{~mL})$, carbon monoxide $(0.1 \mathrm{~mL})$ and carbon dioxide $(0.2 \mathrm{~mL})$ reference gases and $2 \mathrm{~mL}$ of the mixture gas containing ethene, ethane, propane and propene in the $200 \mathrm{~mL}$ vacuum sampling bottle were added to the $1000 \mathrm{~mL}$ vacuum sampling bottles with $984.8 \mathrm{~mL}$ of He gas. The concentrations of the methane, ethyne, ethene, ethane, propene, propane, methylpropane, butane, carbon monoxide and carbon dioxide in these bottles were $100,10,10,10,40,10,60,90,100$, and $200 \mathrm{ppm}$, respectively. This mixture gas was also one of the calibration standard gases.

Concerning the calibration standard gas for hydrogen measurements, 2 and $4 \mathrm{~mL}$ of $\mathrm{He}$ gas were withdrawn from the $200 \mathrm{~mL}$ vacuum sampling bottle filled with He gas using a $10 \mathrm{~mL}$ syringe. Then, 2 and $4 \mathrm{~mL}$ of the hydrogen reference gases were added to the $200 \mathrm{~mL}$ vacuum sampling bottles with 198 and $196 \mathrm{~mL}$ of He gas using a $10 \mathrm{~mL}$ syringe, respectively. The concentrations of hydrogen in the bottles were 10,000 and $20,000 \mathrm{ppm}$.

\section{Gas Chromatography Analysis for Methanol and Ethanol}

Methanol and ethanol were measured using a gas chromatograph (GC-2014, Shimadzu Scientific Instruments Inc.) equipped with a flame ionization detector. Separation was carried out on an Rt-Q-bond column (30 m length, $0.32 \mathrm{~mm}$ i.d., $10 \mu \mathrm{m} \mathrm{d}_{\mathrm{f}}$, Restek Corp., USA) with He gas $(99.999 \%)$ as the carrier gas $(2.15 \mathrm{~mL} / \mathrm{min})$. The detector and injection temperatures were both $250^{\circ} \mathrm{C}$, and $2 \mu \mathrm{L}$ of the sample was injected into the gas chromatograph with the split ratio set at 1:3. The gas chromatograph oven temperature was programmed to be $90^{\circ} \mathrm{C}$ for $3 \mathrm{~min}$, then increased at a rate of $6^{\circ} \mathrm{C} / \mathrm{min}$ to $160^{\circ} \mathrm{C}$ and held at this temperature for $14.5 \mathrm{~min}$.

The calibration standards for these measurements were prepared with methanol (grade for high-performance liquid chromatography 99.7\%, 138-06473, Fujifilm Wako Pure Chemical Corp.) and ethanol (super special grade 99.5\%, 050-00446, Fujifilm Wako Pure Chemical Corp.). $50 \mathrm{~mL}$ of multicomponent stock solution containing methanol and ethanol, both with concentrations of $100 \mathrm{mg} / \mathrm{L}$, was prepared in Milli-Q water. Further, $50 \mathrm{~mL}$ of stock solution containing 2-propanol (guaranteed reagent 99.7\%, 166-04836, Fujifilm Wako Pure Chemical Corp.) with a concentration of $50 \mathrm{mg} / \mathrm{L}$ was prepared in Milli-Q water as an internal standard. The multicomponent stock solution containing methanol and ethanol was diluted with Milli-Q water to make standard solutions with concentrations of $0,0.5,0.76,1.0$ and $2.0 \mathrm{mg} / \mathrm{L}$, which contained $5 \mathrm{~mL}$ of 2-propanol with a concentration of $50 \mathrm{mg} / \mathrm{L} .5 \mathrm{~mL}$ of 2-propanol with a concentration of $50 \mathrm{mg} / \mathrm{L}$ was also added to liquid samples prior to measurement.

\section{High-Performance Liquid Chromatography Analysis for Formaldehyde and Acetaldehyde}

Formaldehyde and acetaldehyde were measured using a high-performance liquid chromatograph (LC-VP system, Shimadzu Scientific Instruments Inc.) equipped with a Shim-pack 
VP-ODS column (150 mm length, $4.6 \mathrm{~mm}$ i.d., Shimadzu Scientific Instruments Inc.) and a photodiode array detector (SPD-M10A, Shimadzu Scientific Instruments Inc.). Separation was performed on the column by isocratic elution with acetonitrile and Milli-Q water (60:40, v/v) as a mobile phase at a flow rate of $0.4 \mathrm{~mL} / \mathrm{min}$. The temperature was $40^{\circ} \mathrm{C}$, the volume of injection was $10 \mu \mathrm{L}$ and the UV detection wavelength was set at $360 \mathrm{~nm}$. The formaldehyde and acetaldehyde in liquid samples were derivatized with 2,4- dinitrophenylhydrazine (DNPH) prior to analysis.

The calibration standards for these measurements were prepared with a formaldehyde 2,4-DNPH standard solution $(40 \mu \mathrm{g} \mathrm{HCHO} / \mathrm{mL}$ acetonitrile solution, 062-03481, Fujifilm Wako Pure Chemical Corp.), acetaldehyde 2,4-DNPH standard solution $\left(0.1 \mu \mathrm{g} \mathrm{CH}{ }_{3} \mathrm{CHO} / \mu \mathrm{L}\right.$ ethyl acetate solution, 012-08861, Fujifilm Wako Pure Chemical Corp.) and acetonitrile (grade for high-performance liquid chromatography 99.8\%, 015-08633, Fujifilm Wako Pure Chemical Corp.). $10 \mathrm{~mL}$ of multicomponent stock solution containing formaldehyde and acetaldehyde with concentrations of 4 and $5 \mathrm{mg} / \mathrm{L}$, respectively, was prepared in acetonitrile. The multicomponent stock solution containing formaldehyde and acetaldehyde was diluted with acetonitrile to make standard solutions. The concentrations in the standard solutions were $0.02,0.04$, and $0.08 \mathrm{mg} / \mathrm{L}$ for formaldehyde and $0.025,0.05$ and $0.1 \mathrm{mg} / \mathrm{L}$ for acetaldehyde.

$0.04 \mathrm{~g}$ of 2,4-DNPH (guaranteed reagent 50\%, 049-03612, Fujifilm Wako Pure Chemical Corp.) was mixed with $15 \mathrm{~mL}$ of a solution containing $25 \mathrm{~mL}$ of Milli-Q water, $2 \mathrm{~mL}$ of $\mathrm{HCl}$ and $13 \mathrm{~mL}$ of acetonitrile. Similarly, $0.04 \mathrm{~g}$ of 2,4-DNPH was mixed with $15 \mathrm{~mL}$ acetonitrile. The 2,4-DNPH was completely dissolved in these solutions using an ultrasonic bath. $0.02 \mathrm{~mL}$ of the former 2,4-DNPH solution was mixed with $1 \mathrm{~mL}$ of each of the liquid samples of the $0.005 \mathrm{M}$ $\mathrm{NaOH}$ solution systems. Similarly, $0.02 \mathrm{~mL}$ of the latter 2,4-DNPH solution was mixed with $1 \mathrm{~mL}$ of each of the liquid samples of the $0.005 \mathrm{M} \mathrm{HCl}$ solution systems. After the reaction for $1 \mathrm{hr}$, the derivatization of these samples was completed and the samples were measured.

\section{Ion Chromatography Analysis for Formic, Acetic and Oxalic Acids}

Formic, acetic and oxalic acids were measured using an ion chromatograph (Dionex ICS-2100, Thermo Fisher Scientific K. K., Japan) equipped with an autosampler (Dionex AS-AP, Thermo Fisher Scientific K. K.). For analytical separation, an IonPac AS19 (250 mm length, 4 mm i.d., Thermo Fisher Scientific K. K.) analytical column and an IonPac AG19 (50 mm length, 4 mm i.d., Thermo Fisher Scientific K. K.) guard column were used. The columns were operated at $35^{\circ} \mathrm{C}$. To reduce background noise and increase the analytical signal output, an ASRS suppressor (working in mode) was used. An eluent generator was used to generate $\mathrm{KOH}$ gradient concentrations. For all analyses in this report, the gradient profile was as follows: $0-2 \mathrm{mmol} / \mathrm{L}$ from 0 to $35 \mathrm{~min}, 2-8 \mathrm{mmol} / \mathrm{L}$ from 35 to $36 \mathrm{~min}, 8 \mathrm{mmol} / \mathrm{L}$ from 36 to $130 \mathrm{~min}, 8-35 \mathrm{mmol} / \mathrm{L}$ from 130 to $131 \mathrm{~min}, 35 \mathrm{mmol} / \mathrm{L}$ from 131 to $160 \mathrm{~min}, 35-2 \mathrm{mmol} / \mathrm{L}$ from 160 to $161 \mathrm{~min}$, and $2 \mathrm{mmol} / \mathrm{L}$ from 161 to $180 \mathrm{~min}$. The eluent flow rate was set at $1 \mathrm{~mL} / \mathrm{min}$ with an injection volume of $25 \mu \mathrm{L}$.

The calibration standards for these measurements were prepared with sodium formate (guaranteed reagent 98.0\%, 190-01995, Fujifilm Wako Pure Chemical Corp.), sodium acetate trihydrate (guaranteed reagent 99.0\%, 198-01055, Fujifilm Wako Pure Chemical Corp.) and sodium oxalate (guaranteed reagent 99.5\%, 198-02655, Fujifilm Wako Pure Chemical Corp). $50 \mathrm{~mL}$ of multicomponent stock solution containing sodium formate, sodium acetate and sodium oxalate, each with a concentration of $20 \mathrm{mg} / \mathrm{L}$, was prepared in Milli-Q water. The 
multicomponent stock solution containing sodium formate, sodium acetate and sodium oxalate was diluted with Milli-Q water to make standard solutions. The concentrations of the standard solutions were $0,0.4,0.8$ and $2.0 \mathrm{mg} / \mathrm{L}$, which contained $2.5 \mathrm{~mL}$ of $\mathrm{NaOH}$ with a concentration of $0.1 \mathrm{~mol} / \mathrm{L}$ to adjust the $\mathrm{pH}$ of the standard solutions to approximate the $\mathrm{pH}$ of the liquid samples. The liquid samples used for measurements were diluted using Milli-Q water if necessary.

\section{Total Organic Carbon Analysis}

Total carbon (TC) and inorganic carbon (IC) concentrations were measured at $680^{\circ} \mathrm{C}$ by the combustion catalytic oxidation/nondispersive infrared method using a total organic carbon analyzer (TOC-V $\mathrm{V}_{\mathrm{CSH}}$, Shimadzu Scientific Instruments Inc.). The TOC concentration was obtained by subtracting the IC concentration from the TC concentration. $22 \mathrm{~mL}$ of a liquid sample was added to a $24 \mathrm{~mL}$ glass vial in glovebox 2 to prevent contamination with carbon dioxide from air. The vials were capped with a silicone septum and screw cap. In addition, the entire vial excluding the top was covered with aluminum foil to prevent radical reactions induced by photon. Then, the vials were removed from glovebox 2 and the IC concentration was first measured. After that, the vials were returned to glovebox 2 and $11 \mathrm{~mL}$ of the liquid sample for which IC analysis had been completed was collected and added to a different $24 \mathrm{~mL}$ glass vial. $11 \mathrm{~mL}$ of $0.1 \mathrm{~mol} / \mathrm{L} \mathrm{HNO}_{3}$ (guaranteed reagent, 60-61\%, 141-01366, Fujifilm Wako Pure Chemical Corp.) was also added to each vial. The vials were also capped with a silicone septum and screw cap and covered with aluminum foil. Then, the vials were removed from glovebox 2 and the TC concentration was measured. At that time, the TC concentration in the used $0.1 \mathrm{~mol} / \mathrm{L} \mathrm{HNO}_{3}$ was also measured.

The calibration standards for these measurements were prepared with potassium hydrogen phthalate (guaranteed reagent 99.8-100.2\%, 163-03822, Fujifilm Wako Pure Chemical Corp.) and sodium carbonate (guaranteed reagent 99.8\%, 195-01582, Fujifilm Wako Pure Chemical Corp.). $100 \mathrm{~mL}$ of stock solution with a TC concentration of $1000 \mathrm{mg} / \mathrm{L}$ was prepared in Milli-Q water using potassium hydrogen phthalate. The stock solution for the TC measurement was diluted with Milli-Q water to make standard solutions with concentrations of $0,2.5,5,10,20$ and $40 \mathrm{mg} / \mathrm{L} .100 \mathrm{~mL}$ of stock solution with an IC concentration of $1000 \mathrm{mg} / \mathrm{L}$ was prepared in Milli-Q water using sodium carbonate. The sodium carbonate was heated in an electric furnace at about $290^{\circ} \mathrm{C}$ for $1 \mathrm{hr}$ and thoroughly cooled in a silica gel desiccator prior to use. The stock solution for the IC measurement was diluted with Milli-Q water to make standard solutions with concentrations of $0,2.5$ and $5 \mathrm{mg} / \mathrm{L}$.

\section{Element Analysis for Fe, Cr, Ni, Mo, Mn and Si}

$\mathrm{Fe}, \mathrm{Cr}, \mathrm{Ni}, \mathrm{Mo}, \mathrm{Mn}$ and $\mathrm{Si}$, which are constituents of the steels, were measured by inductively coupled plasma atomic emission spectroscopy (IRIS Intrepid II XSP DUO, Thermo Fisher Scientific K. K.). Standard solutions with concentrations of $0,0.05,0.1,0.2,0.5$ and $1.0 \mathrm{mg} / \mathrm{L}$ were prepared. Basically, $5 \mathrm{~mL}$ of the liquid sample used to measure for $\mathrm{Fe}, \mathrm{Cr}, \mathrm{Ni}$, Mo and $\mathrm{Mn}$ and $2.5 \mathrm{~mL}$ of $0.1 \mathrm{~mol} / \mathrm{L}^{\mathrm{HNO}_{3}}$ (guaranteed reagent, 60-61\%, 141-01366, Fujifilm Wako Pure Chemical Corp.) were mixed and diluted with Milli-Q water to a total volume of $25 \mathrm{~mL}$. Note that the amount of $\mathrm{HNO}_{3}$ added should be one-tenth of the total volume. In the case of a diluted sample with a concentration exceeding the upper limit of the calibration range, the sample was further diluted with Milli-Q water and $0.1 \mathrm{~mol} / \mathrm{L} \mathrm{HNO}_{3}$. In the case of the liquid sample used to measure for $\mathrm{Si}$, the sample were diluted with Milli-Q water to a concentration within the range of the standard solution. 


\section{$p H, O R P$ and DO Measurements}

The ORP, DO and pH were measured using a handheld ORP meter (RM-30P, DKK-TOA Corp., Japan), a handheld DO meter (DO-14P, DKK-TOA Corp.) and a multi water quality meter (MM-60R, DKK-TOA Corp.), respectively. The measured ORP was with reference to the $\mathrm{Ag} / \mathrm{AgCl}$ reference electrode. The ORP was converted to Eh by adding the ORP value ( $207 \mathrm{~V}$ ) of the $\mathrm{Ag} / \mathrm{AgCl}$ electrode referenced to the standard hydrogen electrode (SHE). The measurement range of DO was between 0 and $19.99 \mathrm{mg} / \mathrm{L}$ and the resolution was $0.01 \mathrm{mg} / \mathrm{L}$.

\section{Particle Size Distribution Analysis}

Dynamic light scattering (DLS) particle size distributions in liquid samples were obtained using a Malvern Zetasizer ZS instrument (Malvern Instruments Ltd., UK), whose size measurement range is from $0.3 \mathrm{~nm}$ to $10 \mu \mathrm{m}$. The liquid samples were filtered using a $0.45 \mu \mathrm{m}$ membrane filter. $1 \mathrm{~mL}$ of each liquid sample was added to a folded capillary cell (DTS1070, Malvern Instruments Ltd.) and measured. The particle size distributions were obtained from three repeat measurements.

\section{TEM-EDS Analysis}

Transmission electron microscopy and energy dispersive spectroscopy (TEM-EDS) analysis was conducted to observe the colloidal carbon in the liquid samples and to validate the elemental composition of colloidal carbon. Approximately $3.5 \mu \mathrm{L}$ of liquid samples of $0.005 \mathrm{M}$ $\mathrm{NaOH}$ or $\mathrm{HCl}$ solution systems were deposited on a 3-mm-diameter molybdenum grid coated with an ultrathin germanium layer (approximately 8 to $13 \mathrm{~nm})(\mathrm{G} 10-\mathrm{M} 05$ STEM Mo50P grid, Okenshoji Co., Ltd., Japan). The samples were dried in a desiccator under vacuum. The samples were observed using a $300 \mathrm{kV}$ field-emission transmission electron microscope (HF-3000, Hitachi High-Technologies Corp., Japan). Compositional information was obtained using an EDS system (SIGMA2, Kevex Corp., USA).

\section{Limit of Quantification and Limit of Detection}

The limit of quantification (LOQ) and limit of detection (LOD) were based on $10 \times$ standard deviation $(\mathrm{SD})$ and $3 \times \mathrm{SD}(\mathrm{n}=10)$ at the lowest calibration level, respectively, of the chemical species and elements.

\section{RESULTS}

\section{Chemical Depth Profile of Stainless-Steel Powders Prior to Use}

The morphologies of the stainless-steel powders after washing with $0.01 \mathrm{M} \mathrm{HCl}$ solution are shown in Figure 2. Some surface nanoparticles were observed but the numbers of the nanoparticles appear to be very small. The chemical depth profiles of the stainless-steel powders after washing are shown in Figure 3. The regions that were analyzed are shown in Figures 2(c) and 2(d). The chemical depth profiles of the type 304L and 316L stainless-steel powders are similar. Silicon and oxygen are dominant at the surface of the particles. Carbon is also present on the surface, although the concentration is lower than those of silicon and oxygen. The concentrations of these elements gradually decrease with increasing depth, while the concentrations of iron, chromium and nickel increase. The oxide thickness was estimated to be approximately $4 \mathrm{~nm}$ for both powders from half the decay of the oxygen content. The oxide layers are mainly composed of $\mathrm{Si}$, which implies that these powders are water-atomized stainless-steel powders (Klar and Samal 2007; Hedberg et al. 2012, 2013), meaning that the stainless-steel powders used 

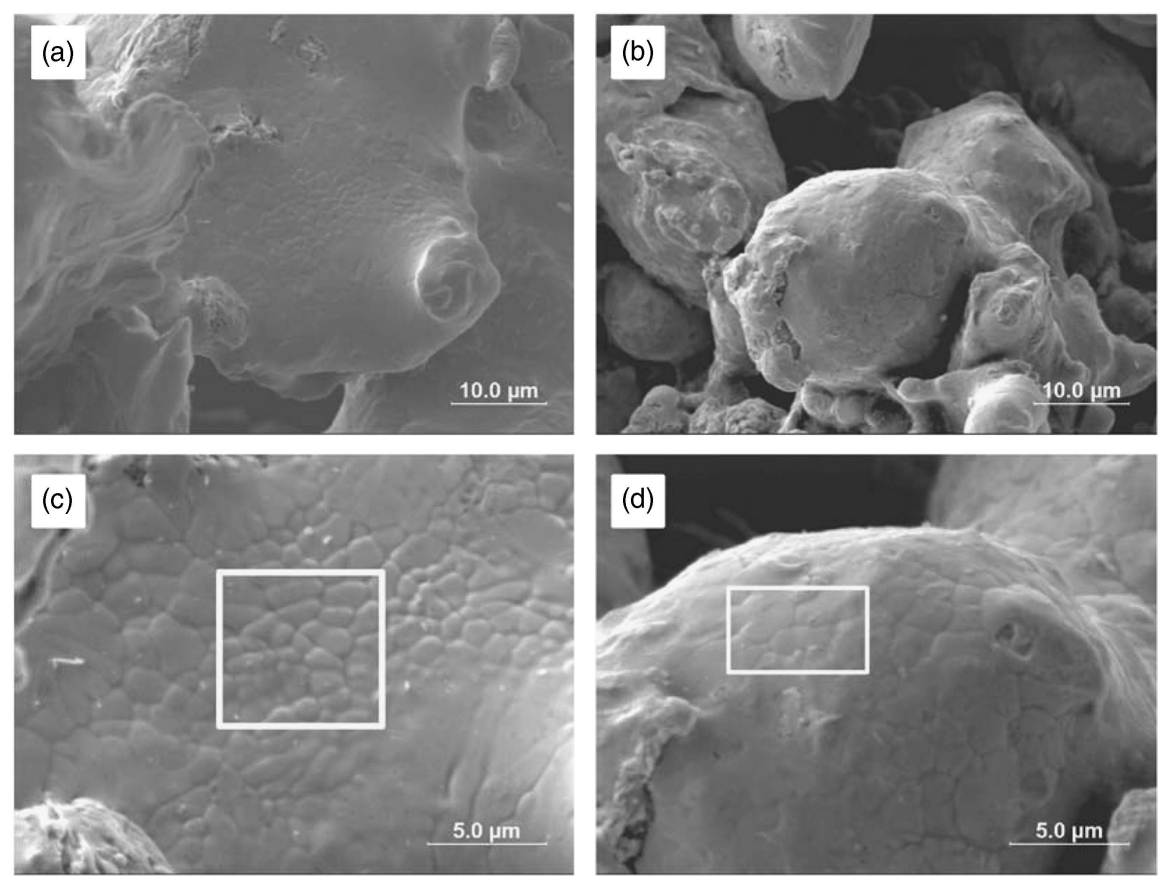

Figure 2 SEM images, at different magnifications, of type 304L stainless-steel powder [(a) and (c)] and type 316L stainless-steel powder [(b) and (d)]. The areas in white rectangles are the AES analysis areas.

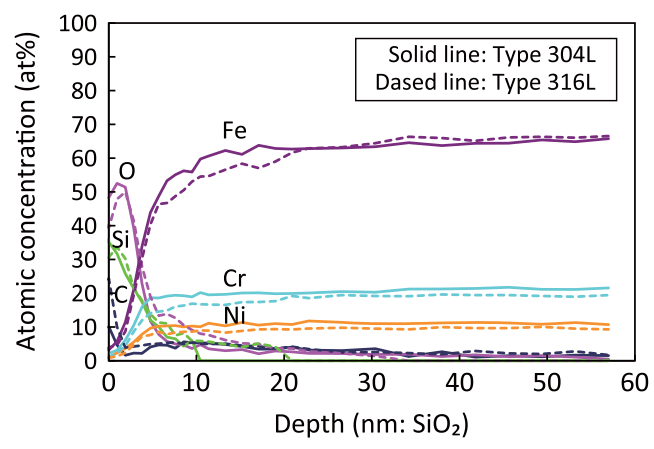

Figure 3 Chemical depth profiles of type 304L and 316L stainless-steel powders.

in this study were produced by a water atomization process. The process essentially consists of the atomization of a stream of liquid metal by high-pressure water jets (Dunkley 1978). A characteristic of a water-atomized powder is that there is a silicon oxide film on the surface of the particles. Owing to the high mobility and oxygen affinity of silicon, silicon diffuses to the surface of the steel droplets and reacts with water vapor to form a protective oxide layer (Tunberg and Nyborg 1995). 


\section{Gas Analysis}

The measurement results of the gas phases in the type $304 \mathrm{~L}$ and $316 \mathrm{~L}$ stainless-steel systems with the $\mathrm{NaOH}$ and $\mathrm{HCl}$ solutions are shown in supplemental Table 1S. No hydrocarbons or carbon monoxide was detected in the type 304L systems with the $\mathrm{NaOH}$ solution. In the type $316 \mathrm{~L}$ systems with the $\mathrm{NaOH}$ solution, only very small amounts of ethene and ethane were detected (the concentration was under the LOQ) and no other hydrocarbons or carbon monoxide was detected. On the other hand, large amounts of hydrogen were detected in both the systems with $\mathrm{NaOH}$ solution. The average hydrogen concentrations in the type 304L and 316L stainless-steel systems with $\mathrm{NaOH}$ solution were 64 and $339 \mu \mathrm{mol} / \mathrm{L}$, respectively.

In the type 304L systems with $\mathrm{HCl}$ solution, ethene, ethane and propane were detected but the concentrations were close to or under the LOQ. In the type $316 \mathrm{~L}$ systems with $\mathrm{HCl}$ solution, ethene and ethane were detected but the concentrations were also close to or under the LOQ. Large amounts of hydrogen were also detected in the systems with the $\mathrm{HCl}$ solution. The average hydrogen concentrations in the type 304L and 316L stainless-steel systems with $\mathrm{HCl}$ solution were 1939 and $308 \mu \mathrm{mol} / \mathrm{L}$, respectively.

The production of hydrogen in this experiment indicates that the reactions in all systems containing the steels occurred in an anaerobic solution. In general, the corrosion of a metal, M, in an anaerobic solution is governed by the following simplest reactions (Stansbury and Buchanan 2000).

$$
\begin{gathered}
\mathrm{M}+\mathrm{mH}^{+} \rightarrow \mathrm{M}^{\mathrm{m}+}+\frac{\mathrm{m}}{2} \mathrm{H}_{2} \text { at } \mathrm{pH}<7 \\
\mathrm{M}+\mathrm{mH}_{2} \mathrm{O} \rightarrow \mathrm{M}^{\mathrm{m}+}+\mathrm{mOH}^{-}+\frac{\mathrm{m}}{2} \mathrm{H}_{2} \text { at } \mathrm{pH} \geq 7
\end{gathered}
$$

\section{Liquid Analysis}

Measurement results for the $\mathrm{pH}$, Eh and DO and the concentrations of the main elements of the liquid phases in the type $304 \mathrm{~L}$ and $316 \mathrm{~L}$ stainless-steel systems with the $\mathrm{NaOH}$ and $\mathrm{HCl}$ solutions are shown in supplemental Table $2 \mathrm{~S}$. The $\mathrm{pH}$ in the $\mathrm{NaOH}$ solution and $\mathrm{HCl}$ solution systems decreased and increased after the reaction between the solutions and steels, respectively. The decrease in the $\mathrm{pH}$ may have been caused by the buffer capacity of the dissolved silica (e.g., $\mathrm{H}_{4} \mathrm{SiO}_{4}(\mathrm{aq})+\mathrm{OH}^{-} \rightarrow \mathrm{H}_{3} \mathrm{SiO}_{4}^{-}+\mathrm{H}_{2} \mathrm{O}$ ) and/or the formation of metallic hydroxides (e.g., $\left.\mathrm{Fe}^{2+}+2 \mathrm{OH}^{-} \rightarrow \mathrm{Fe}(\mathrm{OH})_{2}\right)$. The increase in the $\mathrm{pH}$ may have been caused by the corrosion of the steels, which consume the $\mathrm{H}^{+}$, expressed by Equation (1). The Eh and DO values respectively ranged between approximately 150 and $300 \mathrm{mV} / \mathrm{SHE}$ and between 0.00 and $0.05 \mathrm{mg} / \mathrm{L}$ in the unfiltered samples except for the blank samples. The relatively low DO value is consistent with the production of hydrogen.

Figure 4 shows the concentrations of the main elements above the LOQ in all liquid samples except for the blank samples. In the $\mathrm{NaOH}$ solution systems, the $\mathrm{Fe}, \mathrm{Cr}, \mathrm{Ni}$ and $\mathrm{Mn}$ concentrations were decreased by filtration. This indicates that some of these species could not penetrate the ultrafiltration membranes with 10,000 MWCO and a pore size of approximately $10 \mathrm{~nm}$. The Si and Mo concentrations were hardly changed by filtration. Note that Mo was present as $\mathrm{MoO}_{4}^{2-}$ in the $\mathrm{NaOH}$ solution, which was detected by ion chromatography. On the other hand, in the $\mathrm{HCl}$ solution systems, only the $\mathrm{Cr}$ concentration was decreased by filtration.

The organic carbon compounds and the TC, IC and TOC concentrations in the liquid phases of the type 304 and 316 stainless-steel systems are shown in supplemental Table 3S. Formic and 
(a)

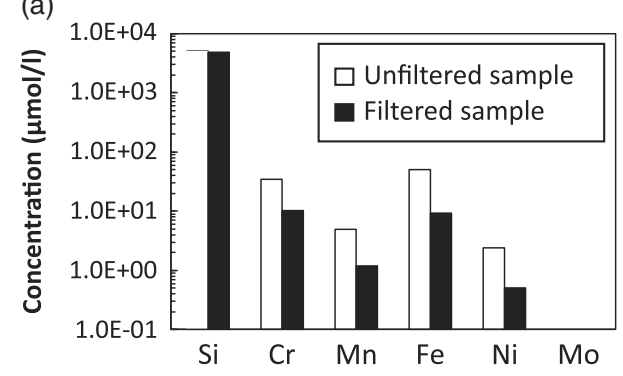

(c)

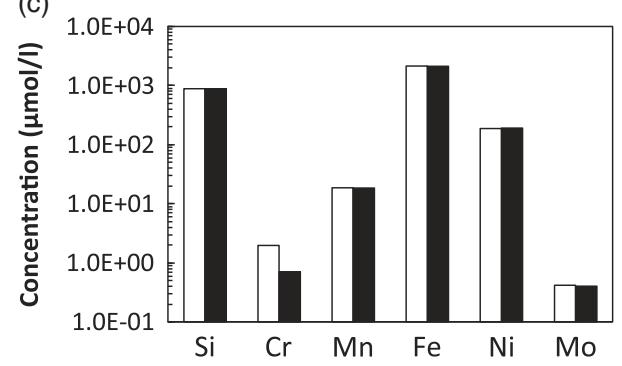

(b)

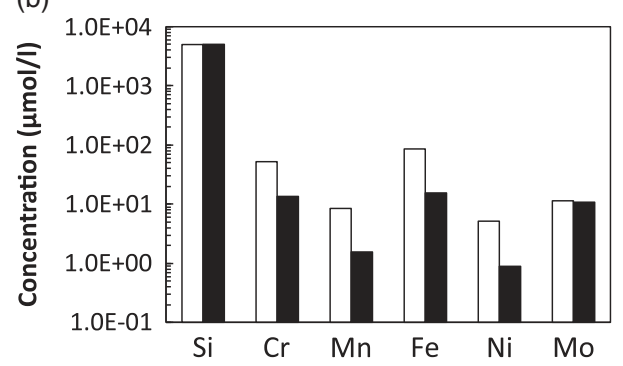

(d)

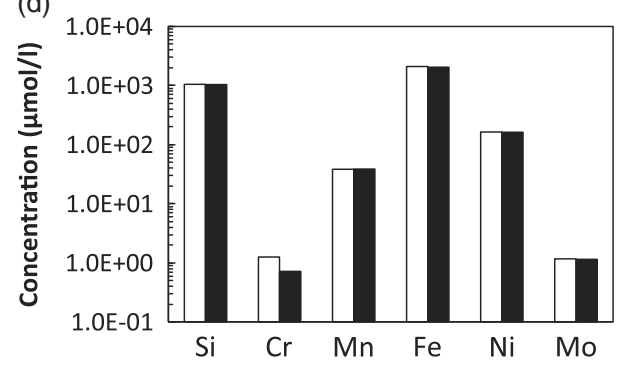

Figure 4 Concentrations of elements for the type 304L (a) and 316L (b) systems in the $\mathrm{NaOH}$ solutions and for the type $304 \mathrm{~L}$ (c) and $316 \mathrm{~L}$ (d) systems in the $\mathrm{HCl}$ solutions.

acetic acids were quantified in all liquid samples except for the blank samples. Oxalic acid was only quantified in the liquid sample of the $\mathrm{NaOH}$ solution system. It appears that there is no difference in the carboxylic acid (formic, acetic and oxalic acids) concentrations before and after ultrafiltration. Other organic carbon compounds (methanol, ethanol, formaldehyde and acetaldehyde) were detected for some samples, although these values were below the LOQ. IC was not detected in all liquid samples. The TOC concentrations in the liquid samples of the unfiltered system were higher than those of the filtered system. This indicates that some of the carbon species could not penetrate the ultrafiltration membrane. These carbon species are referred to as colloidal carbon in this study. The colloidal carbon concentrations of the type 304L and 316L systems are approximately 179 and $190 \mu \mathrm{mol}-\mathrm{C} / \mathrm{L}$ in the $\mathrm{NaOH}$ solution systems and approximately 32 and $25 \mu \mathrm{mol}-\mathrm{C} / \mathrm{L}$ in the $\mathrm{HCl}$ solution systems, respectively. Note that the TOC in the unfiltered blank sample of the $\mathrm{NaOH}$ solution system probably originated from contamination such as the carbon impurity of the $\mathrm{NaOH}$ reagent. The TOC concentrations in the blank samples were one order of magnitude lower than those in the type 304L and 316 L systems in $\mathrm{NaOH}$ solution. Therefore, the effect of the organic carbon originating from contamination is negligible.

Figure 5 shows the concentrations of organic carbon species above the LOQ and the TOC concentration in all liquid samples except for the blank samples. Compared with the $\mathrm{NaOH}$ solution systems, the concentrations of carboxylic acids in the $\mathrm{HCl}$ solution systems were higher and the colloidal carbon concentrations were lower. The sum of the concentrations of the carboxylic acids (formic, acetic and oxalic acids) in the filtered $\mathrm{NaOH}$ solution system was one order of magnitude lower than the TOC concentration, indicating that unidentified carbon compounds were still present in the $\mathrm{NaOH}$ solutions. The unidentified species accounted for about 20 to $23 \%$ of the released carbon, whereas the colloidal carbon accounted for about 
(a)

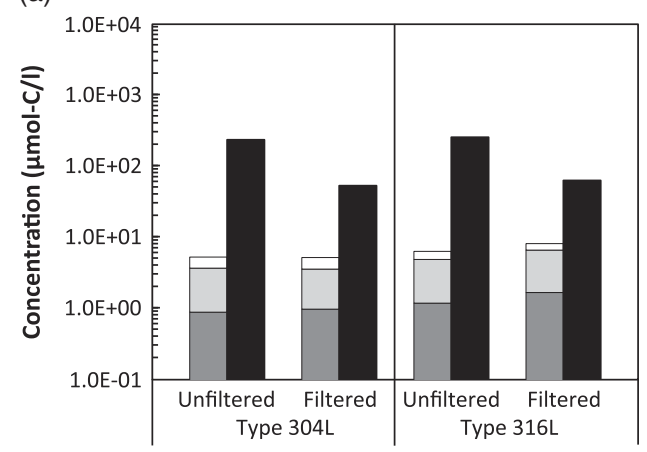

(b)

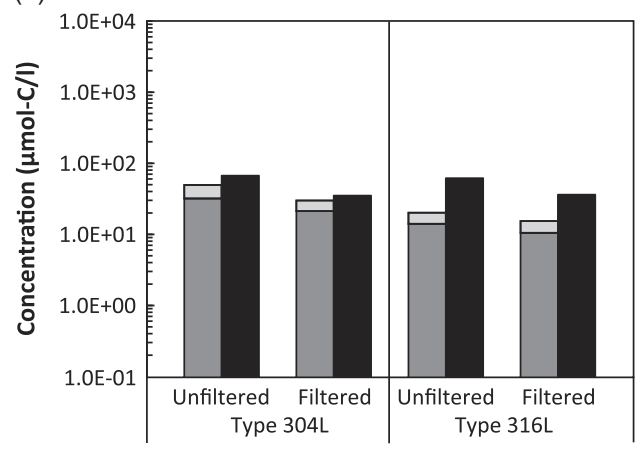

a TOC $\square$ Formic acid $\square$ Acetic acid $\square$ Oxalic acid

Figure 5 Concentrations of carbon species in the $\mathrm{NaOH}$ solutions (a) and $\mathrm{HCl}$ solutions (b).

(a)

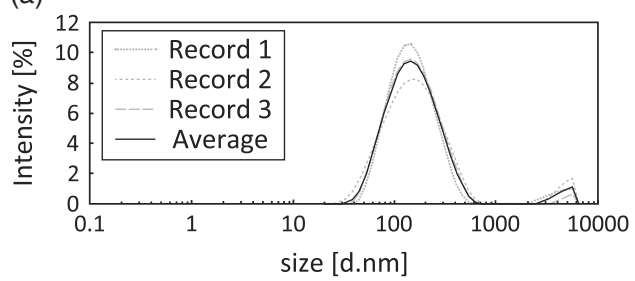

(c)

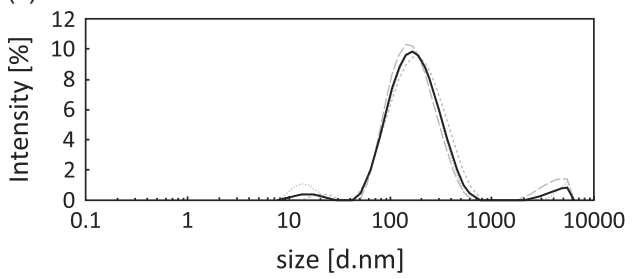

(b)

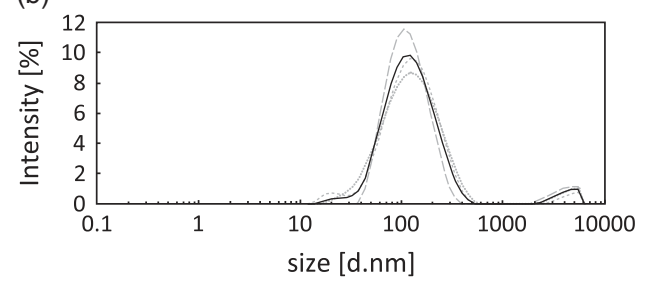

(d)

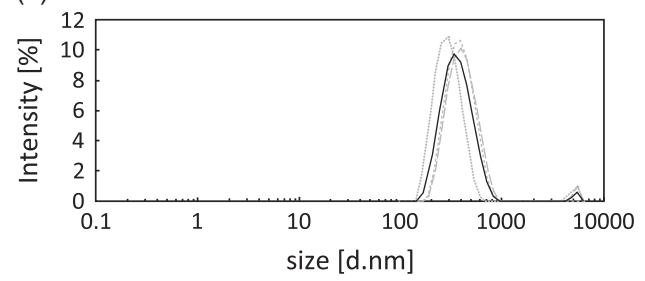

Figure 6 Size distribution of colloidal particles for the type 304L (a) and 316L (b) systems in the $\mathrm{NaOH}$ solutions and for the type $304 \mathrm{~L}$ (c) and $316 \mathrm{~L}$ (d) systems in the $\mathrm{HCl}$ solutions. These samples were filtered using a $0.45 \mu \mathrm{m}$ membrane filter prior to measurement.

75 to $77 \%$ and the carboxylic acids accounted for about 2 to $3 \%$, in the $\mathrm{NaOH}$ solution systems. In the $\mathrm{HCl}$ solution systems, the unidentified species accounted for about 7 to $10 \%$ of the released carbon, whereas the colloidal carbon accounted for about 41 to $48 \%$ and the carboxylic acids accounted for about 44 to $48 \%$.

\section{Characterization of Colloidal Particles}

The DLS measurement showed that there were particles with a size of $10-100 \mathrm{~nm}$ order in the liquid samples filtered using membrane filters with $0.45 \mu \mathrm{m}$ pore size in all the systems (Figure 6). Figure 7 shows TEM images of the colloidal particles in the alkaline systems and the results of point analysis. The nanoparticles appear to have aggregated. The results of point 
(a)

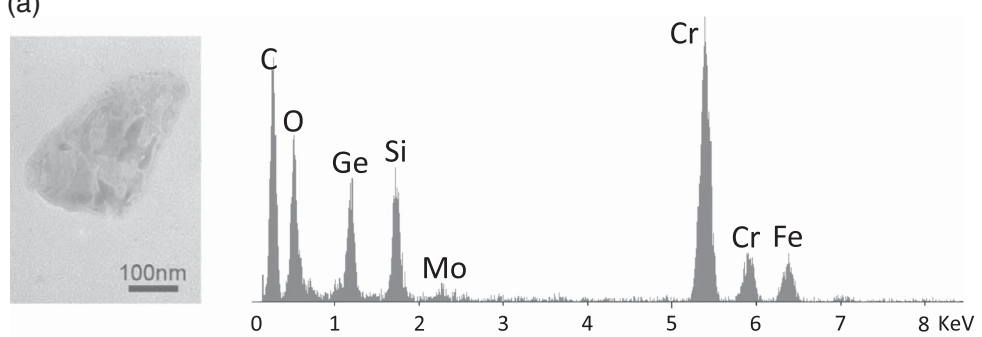

(b)
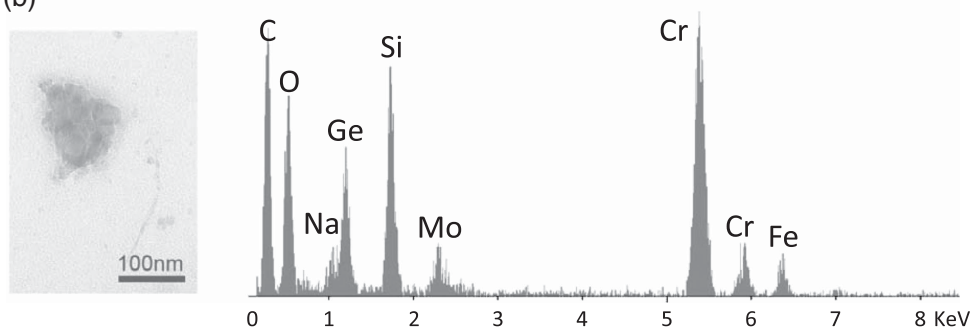

Figure 7 TEM images and EDS spectra of the colloidal particles in the type 304L (a) and 316L (b) systems in the $\mathrm{NaOH}$ solutions. The Mo and Ge peaks originate from the grids used.

analysis showed that carbon was accompanied by $\mathrm{Fe}, \mathrm{Cr}, \mathrm{Si}$ and $\mathrm{O}$ in the particles. In particular, the peak intensities of $\mathrm{Cr}$ and carbon appeared to be higher than the other peak intensities, suggesting that the colloidal carbon may have formed by interactions between carbon and $\mathrm{Cr}$. Although we attempted to observe the colloidal particles in the $\mathrm{HCl}$ solution system, this has not yet been achieved. This is probably due to the low concentration of the colloidal carbon in $\mathrm{HCl}$ solution.

\section{DISCUSSION}

\section{Formation of Colloidal Carbon}

The results in this study showed that colloidal carbon mainly formed in the $\mathrm{NaOH}$ solution systems and that colloidal carbon and carboxylic acids formed in the $\mathrm{HCl}$ solution systems. Here, we discuss the source and the formation mechanism of the colloidal carbon.

First, the following four processes were hypothesized to occur in the formation of the colloidal carbon:

1) Sorption of carbon released from steels on metallic hydroxides,

2) Release of carbon in the base metal in a colloidal form,

3) Release of carbon in the silicon oxide layer in a colloidal form,

4) Release of nanoparticles attached to the steel surface in a colloid form.

Concerning hypothesis 1), Nakabayashi and Fujita (2017) pointed out the possibility that colloidal carbon may be formed by the sorption of carbon, which is released from steels, on metallic compounds (e.g., iron, chromium and nickel hydroxides). If this is the case, it can be expected that colloidal carbon will not be formed under acidic conditions and that metallic 
hydroxides will hardly form. Therefore, an immersion experiment with $\mathrm{HCl}$ solution was performed in this study. The results of the liquid analysis and DLS measurement indicated the possibility that colloidal carbon was present in the $\mathrm{HCl}$ solution systems. Regarding the metallic elements, the concentrations of many elements (i.e., $\mathrm{Mn}, \mathrm{Fe}, \mathrm{Ni}$ and $\mathrm{Mo}$ ) in the $\mathrm{HCl}$ solutions were not changed after the filtration. In contrast, the concentrations of these elements in the $\mathrm{NaOH}$ solutions were decreased by the filtration, indicating that these elements precipitated as hydroxide compounds, as expected. However, only the chromium concentration was decreased by filtration in the $\mathrm{HCl}$ solutions. To discuss which chromium species is the most thermodynamically stable in the $\mathrm{HCl}$ solutions, the $\mathrm{pH}$-Eh diagrams for $\mathrm{Cr}-\mathrm{H}_{2} \mathrm{O}$ systems were calculated (Figure 8). Geochemist's Workbench software with the thermo.com.V8.R6.full thermodynamic database (Bethke 2008) was used. The chromium concentration used for the calculation were the average value of the type $304 \mathrm{~L}$ and $316 \mathrm{~L}$ systems. At the measured values of Eh and $\mathrm{pH}$ in the alkaline systems, $\mathrm{Cr}(\mathrm{OH})_{3}$ is the most thermodynamically stable species in the solution. In contrast, at the measured values of $\mathrm{Eh}$ and $\mathrm{pH}$ in the acidic systems, $\mathrm{CrOH}^{2+}$ is the most thermodynamically stable. The calculation indicated that chromium hydroxide is unlikely to form thermodynamically under the acidic conditions in our present study, which is inconsistent with the suggestion by Nakabayashi and Fujita (2017) that colloidal carbon can be formed by the sorption of carbon on metallic hydroxides. On the basis of the above discussion, it is considered that hypothesis 1 ) is not reasonable.

Concerning hypothesis 2), we discuss the possibility that the carbon in the base metal is released into the liquid phase in a colloidal form. First, the concentrations of carbon released from the base metal of the stainless-steel powders was calculated from the measured concentration of hydrogen using the following equations.

$$
\begin{gathered}
\mathrm{Fe}+2 \mathrm{H}^{+} \rightarrow \mathrm{Fe}^{2+}+\mathrm{H}_{2} \\
\mathrm{Fe}+2 \mathrm{H}_{2} \mathrm{O} \rightarrow \mathrm{Fe}^{2+}+2 \mathrm{OH}^{-}+\mathrm{H}_{2}
\end{gathered}
$$

(a)

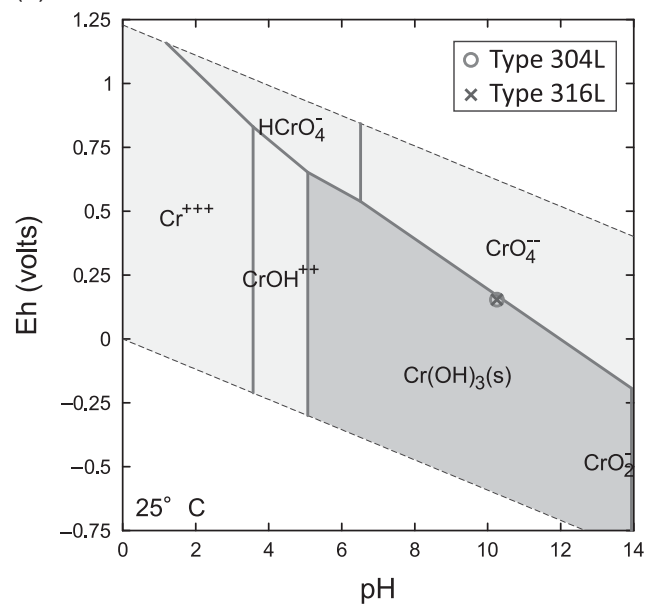

(b)

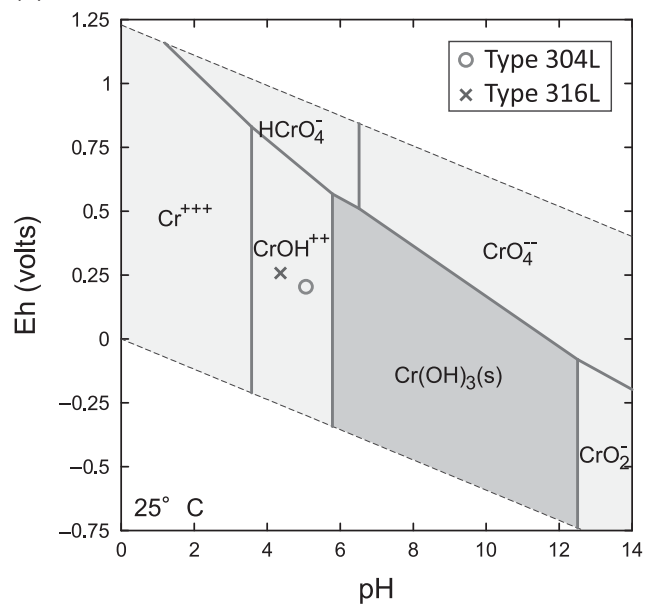

Figure 8 Eh-pH diagrams for $\mathrm{Cr}-\mathrm{H}_{2} \mathrm{O}$ system. The chromium concentration used for the calculation were $43.47 \mu \mathrm{mol} / \mathrm{L}$ (a) for the $\mathrm{NaOH}$ solution system and $1.605 \mu \mathrm{mol} / \mathrm{L}$ (b) for the $\mathrm{HCl}$ solution systems. The open circle and cross mark indicate $\mathrm{Eh}$ and $\mathrm{pH}$ in the unfiltered samples of type $304 \mathrm{~L}$ and $316 \mathrm{~L}$ systems, respectively. The formation of $\mathrm{CrO}_{2}(\mathrm{~s})$ and eskolaite was ignored in the calculation. 
The calculation is based on the assumption that the hydrogen gas is generated in accordance with Equations (3) and (4) in $\mathrm{HCl}$ solution and $\mathrm{NaOH}$ solution, respectively, and that carbon and iron are stoichiometrically released into the solution. The stoichiometric factors of carbon for type $304 \mathrm{~L}$ and $316 \mathrm{~L}$ stainless steels are $1.08 \times 10^{-3}$ and $8.79 \times 10^{-4}$, respectively. These factors are expressed as the carbon/iron $(\mathrm{mol} / \mathrm{mol})$ ratios of the stainless-steel powders, which can be obtained from the molecular weights of the elements and the chemical compositions shown in Table 1. The average hydrogen concentrations given earlier were used in the calculation. The calculated concentrations of carbon for the type $304 \mathrm{~L}$ and $316 \mathrm{~L}$ systems in the $\mathrm{NaOH}$ solutions were 0.02 and $0.09 \mu \mathrm{mol}-\mathrm{C} / \mathrm{L}$, whereas for the type $304 \mathrm{~L}$ and $316 \mathrm{~L}$ systems in the $\mathrm{HCl}$ solutions they were 0.60 and $0.08 \mu \mathrm{mol}-\mathrm{C} / \mathrm{L}$, respectively. These concentrations were significantly lower than the measured concentrations of colloidal carbon of approximately $180 \mu \mathrm{mol}-\mathrm{C} / \mathrm{L}$ in the $\mathrm{NaOH}$ solution systems and approximately $30 \mu \mathrm{mol}-\mathrm{C} / \mathrm{L}$ in the $\mathrm{HCl}$ solution systems, which were given earlier. This indicates that the carbon in the base metal is very unlikely to be released in a colloidal form into the solution.

Concerning hypothesis 3), the results of the AES analysis (Figure 3) showed that a relatively large amount of carbon was present in the silicon oxide layer. Ferriss (1983) conducted a surface analysis of water-atomized powder of type 316L stainless steel by x-ray photoelectron spectroscopy (XPS). It was presumed that the surface carbon was present in the form of hydrocarbons, because the binding energy analyzed by XPS was less than that of carbon in carbides or polymers. In addition, the study pointed out the possibility of hydrocarbons in a silicon oxide layer originating from processing, handling under industrial conditions and deposition by the backdiffusion of vapor in the XPS instrument. The extremely high carbon concentration in the outermost surface in Figure 3 may have been due to contamination during AES analysis for similar reasons to those for the above XPS analysis. Here, the relationship between the silicon and colloidal carbon concentrations in the solutions should be noted. The silicon/colloidal carbon concentration ratios $((\mu \mathrm{mol} / \mathrm{L}) /(\mu \mathrm{mol}-\mathrm{C} / \mathrm{L}))$ for the type $304 \mathrm{~L}$ and $316 \mathrm{~L}$ systems in the $\mathrm{NaOH}$ solution were 28.6 and 26.5 , whereas those for the type $304 \mathrm{~L}$ and $316 \mathrm{~L}$ systems in the $\mathrm{HCl}$ solution were 27.7 and 41.2 , respectively. Note that the silicon concentrations in the unfiltered solutions were used in this calculation. It appears that silicon and colloidal carbon were stoichiometrically released into the solutions. This indicates the possibility that the source of the carbon in the colloidal carbon was the carbon in the silicon oxide layer.

Concerning hypothesis 4), although it was confirmed that nanoparticles were present on the surface of the stainless steels by SEM observation (Figure 2), the number of nanoparticles appeared to be very small. Thus, the assumption that the nanoparticles on the surface of the stainless steels were colloidal carbon is not reasonable.

Given the above discussion, hypothesis 3 ) that the carbon in the silicon oxide layer was released as a colloidal form into the solution is considered to be the most reasonable from the currently available data. However, additional analysis and experiments are necessary to validate the hypothesis. For example, conducting immersion experiments using water-atomized stainlesssteel powders without silicon oxide and/or clarifying the chemical bonding state of the carbon in the colloidal carbon will be helpful for determining the source of the colloidal carbon. In addition, considering long-term safety assessment, it is important to determine whether the colloidal carbon is continuously released into the solution during the corrosion process. Therefore, information on the temporal evolution of the colloidal carbon concentration should be obtained. 


\section{Formation of Carboxylic Acids and Hydrocarbons}

Unlike the colloidal carbon, the concentrations of carboxylic acids (i.e., formic, acetic and oxalic acids) in the $\mathrm{HCl}$ solution systems are one order of magnitude higher than those in the $\mathrm{NaOH}$ solutions. In addition, it appears that the amounts of hydrocarbons generated in the $\mathrm{HCl}$ solution systems are relatively larger than those in the $\mathrm{NaOH}$ solution systems. This indicates that both more oxidized hydrocarbons and more reduced hydrocarbons were generated in the $\mathrm{HCl}$ solution systems than in the $\mathrm{NaOH}$ systems.

Cvetković et al. (2018) performed immersion experiments on unirradiated iron and artificial cement pore water solutions $(\mathrm{pH} 11.0$ to 13.3) under anoxic conditions, and the temporal evolution of the concentration of carbon species in the gas and liquid phases was measured. They proposed that oxidized carbon species (i.e., carboxylic acids, aldehydes, alcohols) could be produced during the exposure of iron particles to oxic conditions, such as during the production or pretreatment of materials prior to use in the experiments, and captured in the oxide layer. These compounds are instantaneously released to the solution upon the immersion of steel, which gives rise to an instantaneous increase in the concentrations of oxidized hydrocarbons. They also proposed that the reduction of hydrocarbons is related to the corrosion of the iron powder.

In our study, the sums of the measured carboxylic acid concentrations, which are those in the unfiltered solution, for the type $304 \mathrm{~L}$ and $316 \mathrm{~L}$ systems in the $\mathrm{NaOH}$ solution were 5.16 and $6.21 \mu \mathrm{mol}-\mathrm{C} / \mathrm{L}$, compared with 49.5 and $20.1 \mu \mathrm{mol}-\mathrm{C} / \mathrm{L}$ in the $\mathrm{HCl}$ system, respectively. These concentrations were two to four orders of magnitude higher than the calculated concentrations of carbon released from the steels given in a previous section. This implies that the carboxylic acids may also have originated from the carbon impurities in the silicon oxide layer. However, it has not been clarified why hardly any of the carboxylic acids formed and colloidal carbon mainly formed in the $\mathrm{NaOH}$ solution, while less colloidal carbon and more carboxylic acids were produced in the $\mathrm{HCl}$ solution. Concerning the hydrocarbons, the estimated carbon concentrations in the solutions were converted to those in the gas phase for comparison with the measured concentration of hydrocarbons. This calculation was based on the assumption that the liquid volume and gas volume in the ampoule were 0.07 and $0.03 \mathrm{~L}$, respectively. The estimated concentrations of carbon for the type $304 \mathrm{~L}$ and $316 \mathrm{~L}$ systems in the $\mathrm{NaOH}$ solutions were 0.05 and $0.21 \mu \mathrm{mol} / \mathrm{L}$, whereas for the type $304 \mathrm{~L}$ and $316 \mathrm{~L}$ systems in the $\mathrm{HCl}$ solutions they were 1.40 and $0.19 \mu \mathrm{mol} / \mathrm{L}$, respectively. These estimated concentrations in the gas phase were close to or under the LOQ and/or LOD of hydrocarbons, indicating the possibility that a significant amount of hydrocarbons was not generated because the immersion duration was very short in our study. The amounts generated were very low, preventing us from discussing the source of the carbon. Considering long-term safety assessment, it is important to determine whether the carboxylic acids and hydrocarbons were continuously released during the corrosion process. To discuss the source of the carbon and the importance of carboxylic acids and hydrocarbons for safety assessment, it is necessary to obtain information on the temporal evolution of the concentrations of the carboxylic acids and hydrocarbons, as conducted by Cvetković et al. (2018).

\section{Applicability of Data Obtained from Water-Atomized Stainless-Steel Powders}

It was revealed that the stainless-steel powders used in this study were produced by the water atomization process. A characteristic of a water-atomized powder is that there is a silicon oxide film on the surface of the particles. In contrast, irradiated stainless steel generated by the 
operation of nuclear power plants has an iron, chromium and nickel oxide layer (Bradbury et al. 1982). It is not yet known whether a difference in the composition of the oxide layer affects the chemical form of carbon released from the stainless steel. In the safety assessment of radioactive waste disposal, it is important not only to determine the chemical form of carbon released from activated stainless steel but also to understand the mechanism of its formation from the viewpoint of the description of safety assessment. In other words, it is important to know whether or not the composition of the oxide layer affects the chemical form of the carbon. For example, the stainless-steel powders produced by the gas atomization process have an iron, chromium and nickel oxide layer (Hedberg et al. 2012, 2013). Comparing the data on the chemical form of carbon released from water-atomized and gas-atomized powders with different oxide compositions could help clarify the effect of the oxide composition on the chemical form of carbon.

The chemical form of ${ }^{14} \mathrm{C}$ in irradiated type $304 \mathrm{~L}$ and $316 \mathrm{~L}$ stainless steels (i.e., radioactive waste) is not yet clear. ${ }^{14} \mathrm{C}$ is mainly produced by the thermal neutron activation of ${ }^{14} \mathrm{~N}$, which is present as a solid solution, in the stainless steel. However, the dominant chemical form of carbon in irradiated stainless steel is not yet known, for example, iron carbide, chromium carbide, or the solid-solution state of carbon. In contrast, the chemical form of the stable carbon (i.e., ${ }^{12} \mathrm{C}$ and ${ }^{13} \mathrm{C}$ ) in the type $304 \mathrm{~L}$ and $316 \mathrm{~L}$ stainless steels used in our study is expected to be the solid-solution state. In general, the carbon content is controlled to a maximum of $0.03 \%$ in stainless steels, which minimizes the problem of carbide precipitation (particularly chromium carbide) during the welding process (Swanton et al. 2015). This study and further studies using water-atomized stainless-steel powders will help to clarify the chemical form of carbon released from the carbon present as a solid solution in the stainless steel.

\section{CONCLUSION}

Immersion experiments using type 304L and 316L stainless-steel powders, which were found to be water-atomized powders, in $\mathrm{NaOH}$ and $\mathrm{HCl}$ solutions under low-oxygen conditions were conducted to determine the chemical form of the stable carbon released from the stainless steels. The results indicated that colloidal carbon mainly formed in the $\mathrm{NaOH}$ solution systems, whereas colloidal carbon and carboxylic acids (i.e., formic and acetic acids) formed in the $\mathrm{HCl}$ solution systems. The amount of colloidal carbon generated in the $\mathrm{NaOH}$ solution was much higher than that in the $\mathrm{HCl}$ solution, while the amount of the carboxylic acids generated in the $\mathrm{HCl}$ solution was higher than that in the $\mathrm{NaOH}$ solution. In both solution systems, almost no hydrocarbons were detected. The colloidal particles observed in the $\mathrm{NaOH}$ solution systems consisted of $\mathrm{C}, \mathrm{Fe}, \mathrm{Cr}, \mathrm{Si}$ and $\mathrm{O}$. In particular, the relationship between $\mathrm{Cr}$ and $\mathrm{C}$ may be involved in the formation of colloidal carbon because the peak intensities of $\mathrm{Cr}$ and $\mathrm{C}$ appeared to be higher than the other peak intensities in the energy spectrum obtained by TEM-EDS.

The concentrations of carbon released from the stainless-steel powders to the liquid phase and gas phase during the corrosion were estimated from the measured concentration of hydrogen in the gas phase. The estimated concentrations of the released carbon in the liquid phase were much lower than the measured concentrations of the colloidal carbon and carboxylic acids. The estimated concentrations of the released carbon in the gas phase were close to or under LOQ and/or LOD of hydrocarbons. Concerning the source of the colloidal carbon, the hypothesis that the carbon in the silicon oxide layer is released into the solution as colloidal carbon is considered to be the most reasonable from the currently available data. The hypotheses that the carbon released form steels sorbed on metallic hydroxides, that the carbon in the base metal was released in a colloidal form and that the nanoparticles attached to the steel surface were released in a colloidal form are not considered to be reasonable. Concerning the source of the carbon in 
the carboxylic acids, they may also have been originated from the carbon in the oxide layer on the basis of a proposal in a previous study. the very small amounts of hydrocarbons generated in our study prevented us from discussing the source of the hydrocarbons. To validate these hypotheses and obtain information on the hydrocarbons, additional analyses and experiments are necessary. In particular, considering the long-term safety assessment, it is important to determine whether the carbon (in the form of colloidal carbon, carboxylic acids and hydrocarbons) is continuously released into the liquid and gas phases during the corrosion process. Therefore, information on the temporal evolution of the carbon concentration should be obtained.

Note that the data obtained in this study were derived from water-atomized stainless-steel powders, which have a silicon oxide film on the surface of the particles. It is considered that the chemical form of stable carbon (i.e., ${ }^{12} \mathrm{C}$ and ${ }^{13} \mathrm{C}$ ) is a solid solution in the powders. In contrast, it is considered that irradiated stainless steel generated by the operation of nuclear power plants has an iron and/or chromium oxide film. The chemical form of ${ }^{14} \mathrm{C}$ in the irradiated stainless steel is not yet clear. Moreover, the effect of the chemical composition of the oxide layer and the effect of the chemical form of carbon in the stainless steel on the chemical form of the carbon released from the stainless steel have not yet been clarified. For the safety assessment of radioactive waste disposal, these effects should be understood.

\section{ACKNOWLEDGMENTS}

The authors would like to thank Katsuaki Kurahashi, Keiko Fukumori and Atsushi Kobayashi (Electric Power Engineering Systems Co. Ltd.) for helping to conduct the experiments and analyze the samples. We are also immensely grateful to Daisuke Sugiyama and Takeshi Ichiji (CRIEPI) for their insightful comments and suggestions.

\section{SUPPLEMENTARY MATERIAL}

To view supplementary material for this article, please visit https:/doi.org/10.1017/ RDC.2018.130

\section{REFERENCES}

Bethke CM. 2008. Geochemical and Biogeochemical Reaction Modeling. 2nd ed. New York: Cambridge University Press.

Blackwood DJ, Gould LJ, Naish CC, Porter FM, Rance AP, Sharland SM, Smart NR, Thomas MI, Yates T. 2002. The localised corrosion of carbon steel and stainless steel in simulated repository environments. AEA Technology Report AEAT/ ERRA-0318.

Bradbury D, Segal MG, Sellers RM, Swan T, Wood CJ. 1982. Decontamination systems of BWRs and PWRs based on LOMI reagents. Proceedings of International Joint Topical Meeting of the American Nuclear Society-Canadian Nuclear Association on the Decontamination of Nuclear Facilities. September 19-22, 1982. Niagara Falls, Ontario.

Cvetković BZ, Rothardt J, Büttler A, Kunz D, Schlotterbeck G, Wieland E. 2018. Formation of low-molecular-weight organic compounds during anoxic corrosion of zero-valent iron. Environmental Engineering Science 35(5):447-61.
Dunkley JJ. 1978. The production of metal powders by water atomisation. Powder Metallurgy International 10(1):38-41.

Ferris DP. 1983. Surface analysis of steel powders by ESCA. The International Journal of Powder Metallurgy \& Powder Technology 19(1): 11-9.

Hedberg Y, Norell M, Linhardt P, Bergqvist H, Wallinder IO. 2012. Influence of surface oxide characteristics and speciation on corrosion, electrochemical properties and metal release of atomized $316 \mathrm{~L}$ stainless steel powders. International Journal of Electrochemical Science 7:11655-77.

Hedberg Y, Norell M, Hedberg J, Szakálos P, Linhardt P, Wallinder IO. 2013. Surface characterisation of fine inert gas and water atomised stainless steel $316 \mathrm{~L}$ powders: formation of thermodynamically unstable surface oxide phases. Powder Metallurgy 56(2):158-63.

Klar E, Samal PK. 2007. Powder Metallurgy Stainless Steels: Processing, Microstructures, and Properties. Materials Park $(\mathrm{OH})$ : ASM International. 
Mihara M, Nishimura T, Wada R, Honda A. 2002. Estimation on gas generation and corrosion rates of carbon steel, stainless steel and zircaloy in alkaline solutions under low oxygen condition. Saikuru Kiko Giho 15:91-101. In Japanese.

Nakabayashi R, Fujita T. 2017. Identification of chemical form of carbon released from SUS304 and SUS316 in alkaline solution under low-oxygen condition. MRS Advances 2(11):597-602.

Nuclear Safety Commission of Japan, Special Committee on Radioactive Waste and Decommissioning. 2007. Upper Bounds of Radioactive Concentration in Burial of Low-Level Radioactive Solid Waste. Tokyo. In Japanese.

Stansbury EE, Buchanan RA. 2000. Fundamentals of Electrochemical Corrosion. Materials Park $(\mathrm{OH})$ : ASM International.
Stumm W, Morgan JJ. 1996. Aquatic Chemistry: Chemical Equilibria and Rates in Natural Waters. New York: Wiley Interscience.

Swanton SW, Baston GMN, Smart NR. 2015. Rates of steel corrosion and carbon-14 release from irradiated steels-state of the art review. CAST WP2 Deliverable 2.1.

Tunberg T, Nyborg L. 1995. Surface reactions during water atomisation and sintering of austenitic stainless steel powder. Powder Metallurgy 38 (2):120-30.

Yamato A. 2006. The current status of the JNFL subsurface disposal plan for relatively high low level radioactive waste. Proceedings of an International Conference on the Safety of Radioactive Waste Disposal. October 3-7, 2005. Tokyo. 